\title{
Chapter 31 \\ How Clean Is the Air You Breathe? Air Quality During Commuting Using Various Transport Modes in Nottingham
}

\author{
Bubaker Shakmak, Matthew Watkins, and Amin Al-Habaibeh
}

\begin{abstract}
Air quality has developed into a significant global issue and its negative effect on human health, wellbeing and ultimately the effect of shortening of life expectancy is becoming a pressing concern. Such concerns are most acute in cities in the UK. Although many cities, including Nottingham, are taking significant measures to enhance air quality, there was limited work focusing on the individual's experience during commuting. This paper suggests a novel approach for measuring commuting air quality through quantifying particulate matters PM2.5 and PM10, using the city of Nottingham as a case study. Portable low-cost systems comprising of a GPS sensor and an Aeroqual pollution data logger were used to capture data and develop the sensor fusion via newly developed software. Data was collected from a variety of transport modes comprising bike, bus, car, tram and walking to provide evidence on relative particulate levels and $2 \mathrm{D}$ and $3 \mathrm{D}$ data maps were produced to communicate the relative pollution levels in a publicly accessible manner. The study found as expected particulate pollution to be higher during peak hours and typically closer to the city. However whilst the lowest particulate concentrations were found on the Tram the highest were for cyclists contrary to the literature. The project encompasses a democratic crowd sourced approach to data collection by enabling the public to gather data via their daily commute, increasing people's awareness of the air quality in their locality. The acquired data permitted a range of comparisons considering differing times of day and zones such as the city centre and surrounding residential areas in the City council boundary.
\end{abstract}

Keywords Air quality $\cdot$ Monitoring $\cdot$ Transport mode $\cdot$ Mapping $\cdot$ Crowd sourcing

B. Shakmak $\cdot$ M. Watkins $(\bowtie) \cdot$ A. Al-Habaibeh

School of Architecture and the Built Environment, Nottingham Trent University, Nottingham, UK e-mail: Matthew.Watkins@ntu.ac.uk

B. Shakmak

e-mail: Bubakar.Shakmak@ntu.ac.uk

A. Al-Habaibeh

e-mail: Amin.Al-Habaibeh@ntu.ac.uk

I. Mporas et al. (eds.), Energy and Sustainable Futures, Springer Proceedings in Energy, https://doi.org/10.1007/978-3-030-63916-7_31 


\subsection{Introduction}

The dangers of air pollution are well documented and exposure to the particulate matter in the air is a significant contributor to cardiovascular disease and can lead to an increase in premature death rates $[1,6]$. Air quality monitoring is therefore important in regard to protecting human health but also the environment [2].

Nottingham is one of 44 UK cities that exceeded safe levels of air quality in 2017 $[3,6]$. The World Health Organisation (WHO) states that particles (PM 2.5) in the air should not exceed 10 micrograms per cubic metre, whilst in Nottingham, it was 12 micrograms per cubic metre at its peak [3]. Over recent years Nottingham has significantly reduced its air pollution levels by investing in public transport, active travel infrastructure and discouraging private car use through a workplace parking levy $[4,6]$. However, in order to continue to drive down air pollution public engagement is also important. Public engagement could be increased through awareness of the issues and this project proposes a potential solution by utilising public crowdsourced data to continually update a pollution map to identify the most polluted areas, for use as an early alarms system and to identify and address pollution hotspots. This project aims to produce and test an inexpensive, easy to use, yet effective technology to monitor pollution and air quality around the city of Nottingham, utilizing citizens to collect data through their daily commute and leisure travel. Particulate Matter (PM) data collected with GPS coordinates will permit the creation of pollution maps, by location and transport mode.

\subsection{Methodology}

This study utilised modified backpacks shown in Fig. 31.1 each containing an Aeroqual Series 500 air quality monitor with a particulate matter sensor able to measure PM 2.5 \& PM 10, with an ITrail GPS coordinate tracking unit enabling the data to be analysed and overlaid in processing later. The choice of both the PM sensor and
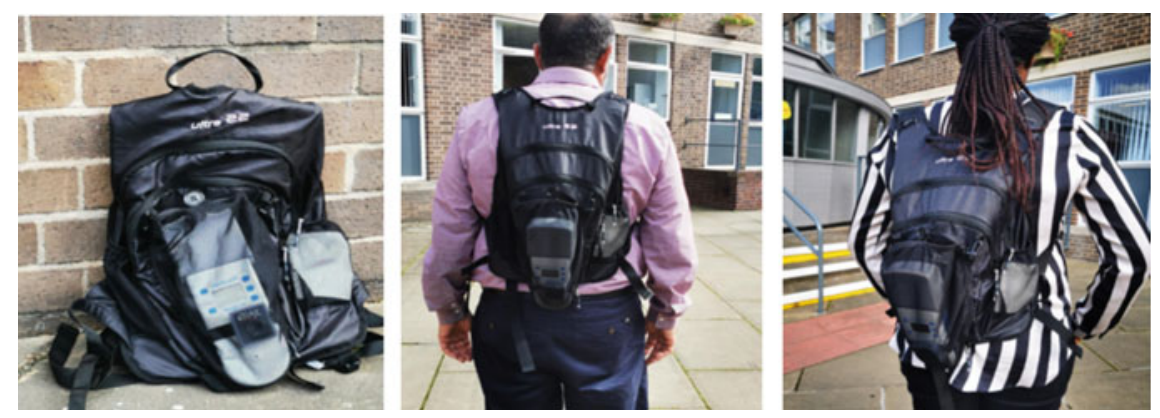

Fig. 31.1 Depicting the integrated device placed inside a backpack 
GPS unit were made according to accuracy, low weight, and portability and battery life. Volunteers were asked to carry the backpack with them for 1-2 days each and volunteers were selected to replicate journeys from different areas into the city centre using a variety of transport modes including walking, cycling, bus, car and tram. The data was collected in three months between April and July 2019. Between them the volunteers covered approximately half of the Nottingham city area.

\subsection{Pollution Data Processing}

The inclusion of the GPS tracker permitted the location coordinates to be recorded to an accuracy of $\pm 3 \mathrm{~m}$ and aligned and processed with the pollution data by matching the time and date stamps from each device within Matlab software, at which point the mode of transport would be added from notes.

Proprietary software was created which permits the classification of the GPS coordinates to align with six pre-determined city zones. The six zones were determined based on the location of the participants commute and the distance from the city centre, growing between $1 \& 2$ miles in diameter as shown in Fig. 31.2.

The data was thoroughly checked and cleaned to remove duplicates before being analysed and used to plot the pollution maps shown in Fig. 31.3. The Matlab code created enabled automatic sifting of the data to filter the data based on variables and associated categories to carry out practical comparisons. The data has been marked for each transportation method in order to carry out some sort of comparison to identify the safest mean of transportation for a human without being exposed to extra-polluted air.

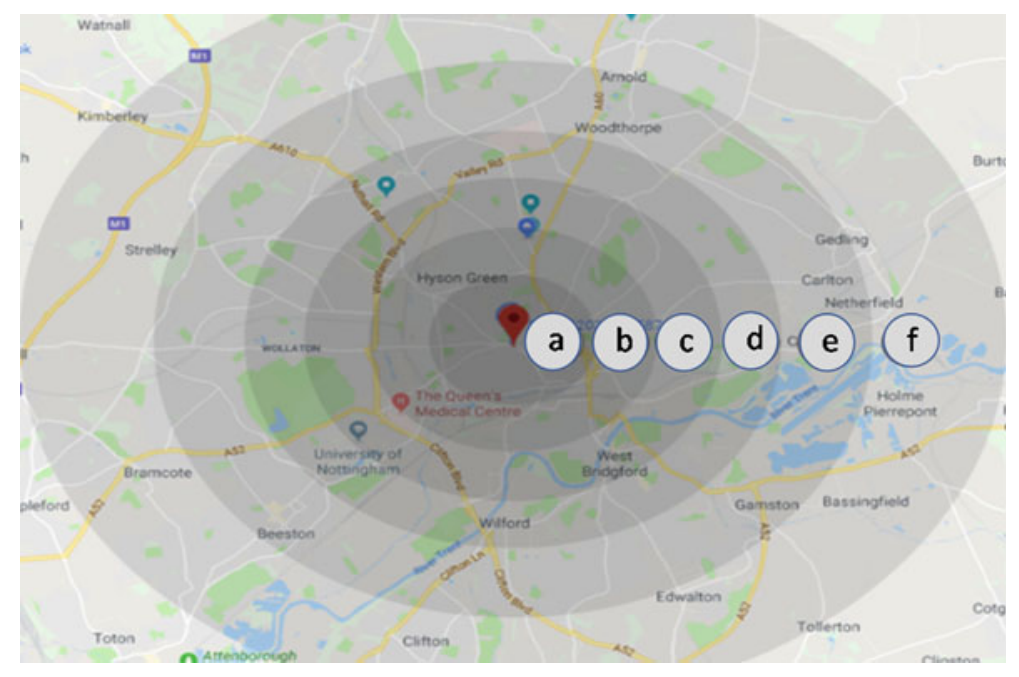

Fig. 31.2 Map of the six zones in Nottingham 

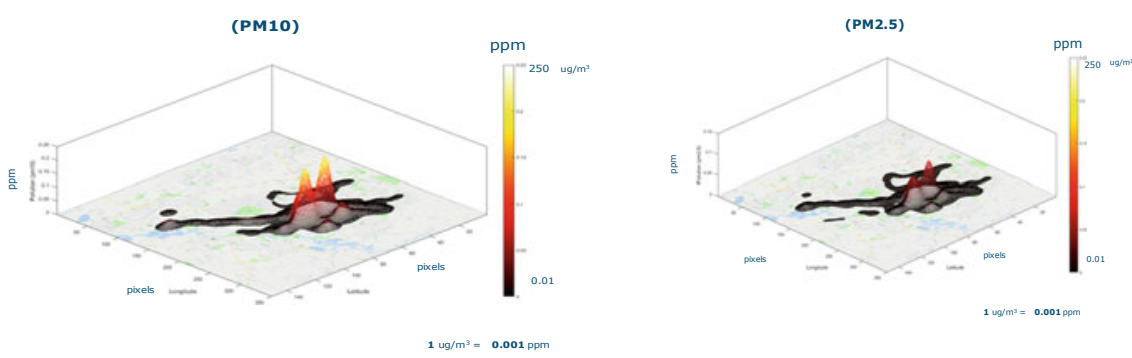

Fig. 31.3 Particulate (PM10 \& PM2.5) Relief Maps of Nottingham

\subsection{Results and Discussions}

The processed data was converted and overlaid on maps to create a $3 \mathrm{D}$ relief for both PM10 and PM2.5 pollution types, visually representing the status of pollution around the city. These maps illustrate the paths used by the volunteers to collect the samples of the pollution data and the amount of pollution around the city for PM10 and PM 2.5 as shown in Fig. 31.3 respectively.

The range of samples recorded by transport mode as shown below in Table 31.1, whilst the sample was especially high for walking this is to be expected as with all transport modes an element of walking is undertaken at either end of the trip and even between modes in some cases. Furthermore due to this being a city centre location walking as the main mode is more likely, especially amongst student participants.

The travel modes were compared and an average taken across each as shown in Fig. 31.4. The Bus had the highest PM 10 values, whilst cycling the highest PM2.5 values. This is surprising considering that by this time much of the council bus fleet is Biogas powered. The tram had the lowest values in both measurements, which could be partly explained by the fact that Trams routes can include sections of road where motor vehicles are prohibited. However cars had the 2nd lowest readings, which is contrary to published guidance, especially in relation to cyclists [5]

Table 31.1 Number of samples and the percentage taken by each transportation mode

\begin{tabular}{l|l|l|l|l|l}
\hline Mode & Walk & Bicycle & Car & Bus & Tram \\
\hline No samples & 3108 & 291 & 243 & 359 & 195 \\
\hline Percentage (\%) & 74 & 7 & 6 & 9 & 5 \\
\hline
\end{tabular}




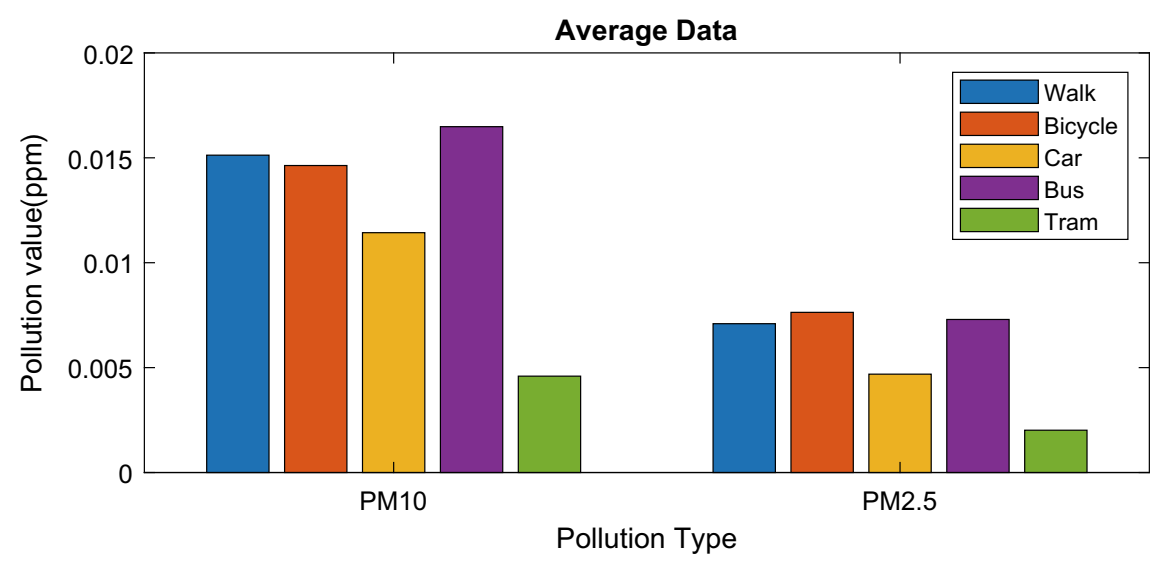

Fig. 31.4 The mean PM data acquired by transportation modes

Table 31.2 Time frame categories

\begin{tabular}{l|l|l|l}
\hline From & To & Description & Time Interval \\
\hline $00: 00$ & $06: 00$ & Quiet morning time & A \\
\hline $06: 00$ & $08: 00$ & Early morning hours & B \\
\hline $08: 00$ & $10: 00$ & Rush hours & C \\
\hline $10: 00$ & $16: 00$ & Working hours & D \\
\hline $16: 00$ & $18: 00$ & Evening rush hours & E \\
\hline $18: 00$ & $21: 00$ & Evening social hours & F \\
\hline
\end{tabular}

\subsubsection{Effect of Time of Day}

To gain further insight Matlab analysis considered the timestamps dividing the data into seven categories as shown in Table 31.2, to consider the effects of road congestion. As expected Fig. 31.5 shows pollution is typically higher during rush hours periods, but this appears to continue even later than expected until $9 \mathrm{pm}$.

\subsubsection{Zonal Considerations}

By comparing the pollution across the 6 zones (introduced in Fig. 31.2), Fig. 31.6 demonstrates that the amount of pollution in the centre of the city is high with the pollution reducing towards the outskirts of the city. The average of both PM10 and PM2.5 shows the pollution values are higher in the city centre and typically decreasing with distance outside of the city. However Zone e appears to be an 
The Average Pollution Levels

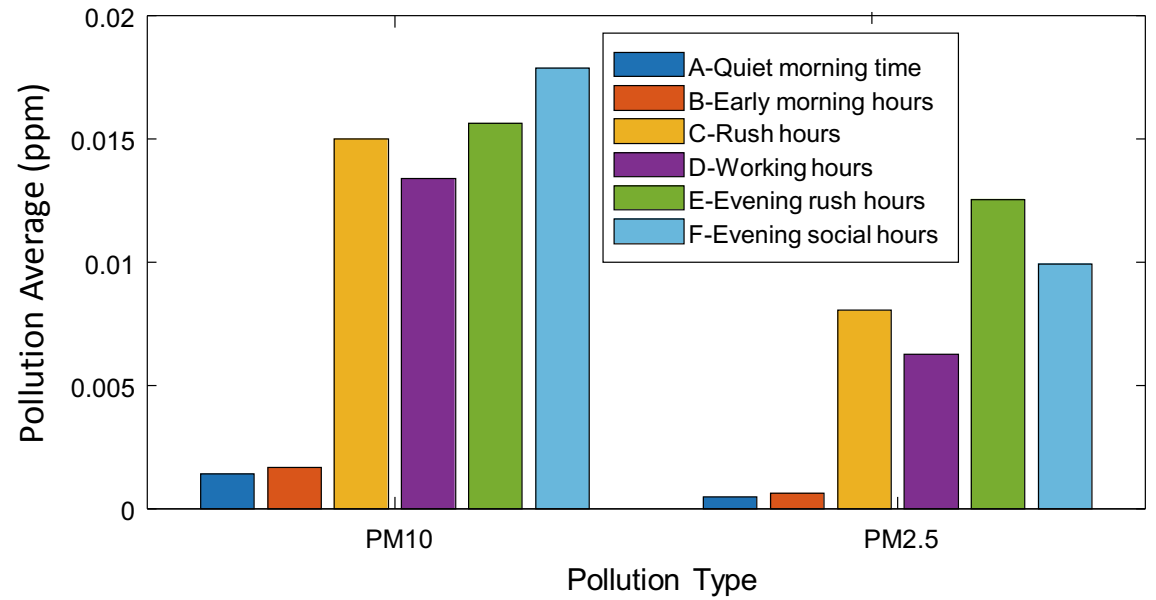

Fig. 31.5 The average pollution data by time of day

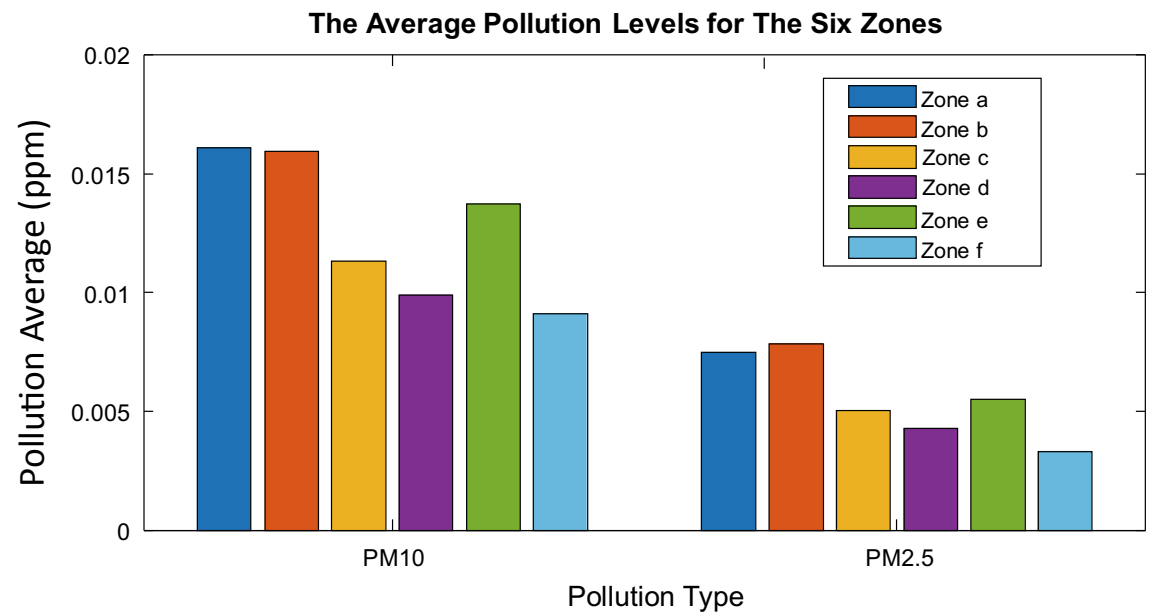

Fig. 31.6 The average of the pollution in the six zones around Nottingham

anomaly, but upon investigation appeared there was a higher deviation in the readings from Zone e which could account for this and so a larger and longer term sample needs to be conducted to explore this further. 


\subsection{Conclusions}

The study suggests that a crowdsourced approach to monitoring air quality levels is viable and has potential to be highly effective. The results typically follow expected patterns with higher levels typically closer to the city centre and higher concentrations at peak times. However the results also highlight some surprising results in relation to the transport mode and further research considering this would be beneficial. Of particular interest is the highest level of PM2.5 when cycling, which combined with the additional aerobic exercise, requiring deeper breathing could have pose long-term health issues with particulates entering the lungs.

\subsection{Further Work}

The team will continue this research, focussing specifically in relation to cycling exploring air quality over longer durations, with a number of weeks per participant repeating a set commute to and from set key locations into the city centre. This work will consider a wider range of air pollutants using multiple sensors and will be repeated at different times of the year to consider the effects of seasonal changes. It is also hoped to develop a dedicated application to be used in mobile phones when connected to the device to manage and send the data remotely to the network.

Acknowledgements This study was funded via the NTU Sustainable Futures Seedcorn.

\section{References}

1. R.D. Brook et al., Particulate matter air pollution and cardiovascular disease: an update to the scientific statement from the american heart association. Circulation 121(21), 2331-2378 (2010)

2. Why Air Quality is important, Oxfordshire AirQuality. [Online]. https://oxfordshire.air-quality. info/why-air-quality-is-important. Accessed 18 Sep 2019

3. J. Pritchard, "Nottingham air does not meet safe levels says major new report, Nottingham Post (2017). https://www.nottinghampost.com/news/nottingham-news/nottingham-air-too-dan gerous-breathe-704643. Accessed 29 June 2020

4. C. Reid, Nottingham's Workplace Parking Levy Creates Jobs, Cuts Car Use and Slashes Pollution, Forbes (2019). https://www.forbes.com/sites/carltonreid/2019/10/17/nottinghams-workpl ace-parking-levy-creates-jobs-cuts-car-use-and-slashes-pollution/. Accessed 24 June 2020

5. A. Karanasiou, M. Viana, X. Querol, T. Moreno, F. de Leeuw, Assessment of personal exposure to particulate air pollution during commuting in European cities-Recommendations and policy implications. Sci. Total Environ. 490, 785-797 (2014)

6. Nottingham City Council, Nottinghamshire Air Quality Strategy 2019-2028 (2019). https:// committee.nottinghamcity.gov.uk/documents/s97117/Enc. 1 for Draft revised Nottingham and Nottinghamshire Air Quality Strategy.pdf. Accessed 29 June 2020 
Open Access This chapter is licensed under the terms of the Creative Commons Attribution 4.0 International License (http://creativecommons.org/licenses/by/4.0/), which permits use, sharing, adaptation, distribution and reproduction in any medium or format, as long as you give appropriate credit to the original author(s) and the source, provide a link to the Creative Commons license and indicate if changes were made.

The images or other third party material in this chapter are included in the chapter's Creative Commons license, unless indicated otherwise in a credit line to the material. If material is not included in the chapter's Creative Commons license and your intended use is not permitted by statutory regulation or exceeds the permitted use, you will need to obtain permission directly from the copyright holder.

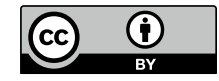

